\title{
The personality of the future teacher in the con- text of the challenges of the innovation space
}

\author{
Tatyana Shcherbakova ${ }^{1, *}$, Dinamutdin Misirov $^{2}$, Tatyana Guseva ${ }^{2}$, Nadezhda Alexan- \\ drova $^{2}$, and Yegor Shostak ${ }^{2}$ \\ ${ }^{1}$ Don State Technical University, 344003, 1, Gagarina Square, Rostov-on-Don, Russia \\ ${ }^{2}$ Southern Federal University, 344065, 116, Dneprovskiy street, Rostov-on-Don, Russia
}

\begin{abstract}
The paper systematizes approaches to the study of the higher school teacher's work, presents the results of the analysis of the psychological component of his professional self-effectiveness in the space of modern innovations. The content of the article reveals the features of the teacher as a subject of professional activity in the educational environment of the University. The article describes the psychological determinants of success of teacher in terms of resources and risks of modern innovation space, presented mechanisms of development and manifestations of occupational success factors, conditions, strategies and professional development of the teacher of the future, reflecting the current format of supporting the development of the subject training. The article describes the phenomenological and instrumental components of success, factors and conditions for the formation of successful professional behavior, as well as forms and ways of representing success in interaction with students. The article shows the psychological function of competence and reference in the professional activity of a higher school teacher, the role of sociogenic needs of a teacher in self-development, personalization, self-actualization and self-realization in interaction with students. Features of interpretation of the personality image of the future teacher from the point of view of modern students are presented.
\end{abstract}

\section{Introduction}

The increasing dynamism of various types of innovations and diverse transformations in the modern world and in the field of higher education, among other things, places special demands on the ability of a teacher to preadapt his psychological resources and individual opportunities to achieve success as a subject of professional activity and, in General, life activity. For the teacher of the future, achieving professional, social and personal success is a significant value of life, as it is intended to convey success to students as an indicator of personal well-being, competence, resourcefulness and competitiveness. In the system of higher professional education, its image, behavior and performance act as an active facilitating tool that contributes to the formation of attitudes to competence and success among

Corresponding author: tatiananik@list.ru 
future specialists of the agro-industrial complex [1-2]. The period of study at the University plays a unique role in shaping the focus on professional success and productivity, due to the very specifics of the social situation of development at this stage of becoming a future specialist. As a student, a person gets the opportunity to master various socio-psychological roles, has a diverse palette of samples of professional skills, interacts with really successful professionals. However, here in the context of communication with the teacher is a correction initial career and life plans, developing a dynamic relationship to the profession, it complicates and deepens the relationship to itself as subject of future professional activities, accumulate knowledge and form competences, testing resources, identifying risks, specified goals, define future plans, to build an individual trajectory of advancement in the profession.

Psychologists note that the psychological focus of higher professional education is the implementation of independent life choices associated with determining the ways of further professional development and taking responsibility for the choice made.

At the University level, in cooperation with teachers, professional activities are designed that are included in the context of a person's life path and have a life value in accordance with their own purpose and mission.

A. G. Asmolov speaks about higher professional education as a purposeful system of socialization of the individual, as a space for expanding the opportunities for professional growth in the future [3]. It is important to understand that the reform of higher professional education implies a restructuring, a comprehensive transformation of the life of subjects, and not only the modernization of teaching methods and technologies. The research of modern psychologists shows that during professional training in higher education, students may feel a certain crisis, experienced as a sense of uncertainty in their own abilities, increased anxiety about their own future, doubts about the correctness of choosing a profession [4].

Solving the problem of meaning, revealing the meaning of professional activity, its projections into different spheres of life, and forming the personal meaning of activity contributes to the formation of a future professional's personality.

The importance of studying the predictors of success of a higher school teacher increases in the situation of increasing immersion in the information educational environment, where he must be competitive and competent.

Currently, there are certain risks associated with the features of the modern innovation space. The acquisition of knowledge, including theories, concepts, concepts, and training procedures, is now a problem associated with the fact that their diversity can lead to inconsistency. Here, the personal qualities of the teacher, the nature, dynamics, originality of the simulated interpersonal relationships, the nature of the presentation of information affect the result of learning and ultimately the quality of education. Moreover, the professional worldview of a teacher is "immersed" in the system of actual socio-cultural ideas about a person and the world that determine his professional position and style of activity [5-7].

Today, a high school teacher fulfills an important social mission of transforming an adequate generalized, personalized modern world and its scientific picture [8].

Ultimately, today it is important to identify the determinants that determine the degree of internal freedom, motivation of achievements that contribute to the development of competence of a modern specialist and his / her self-identity [9]. In psychology, it is shown that professional identity is formed by reflection, self-attitude and acceptance of the specifics of professional life. Professional activity of a higher school teacher today is the embodiment of professional and life meanings. From the point of view of psychologists, the subject's understanding of the meaning of a certain attitude to the world requires a complex and specific autopsychological activity of understanding and evaluating life, solving a special "task for meaning" [10-12]. Today, a different meaning is becoming increasingly important at the 
individual level, which is associated with the transitivity of modern society, overcoming, self-overcoming and self-transformation, and the realization of the ability to preadapt [3]. The activity itself can be given meaning, and the satisfaction of the sociogenic need for prestige, authority, fame, recognition, respect, status, and material reward act as collateral results. The personality here is forced to self-actualize, self-actualize in this type of activity, it strives for creativity and positive transformations. In obtaining success-vocation, the semantic content of success for subjects is revealed [13-15].

The expressed professional identity testifies to the importance of the profession for a teacher as a space for satisfying their needs, self-realization, and self-fulfillment.

\section{Purpose of Investigation}

The purpose of the study was to study students ' ideas about the personality of a successful teacher and a teacher of the future.

\section{Methods of Investigation}

The following methods were used as diagnostic tools: author's questionnaire: "Teacher of the future" and "Image of the teacher".

The practical significance of the research is connected, first of all, with the fact that the theory and methods of teaching appear alive and acquire a facilizing status only when they pass through the personal experience of the teacher, and his personality becomes referential in the eyes of students. The teacher today acts as a moderator and scientist, integrating feelings and experience with a professional choice of methods and tools.

The study involved students of the agro-industrial faculty and the faculty of psychology, defectology and pedagogy of DSTU, in the number of 157 respondents.

\section{Results}

Summarizing the results of the study, the following personality traits can be identified that are professionally significant for a modern teacher in the system of higher professional education:

- concentration on the student's desire and ability to contribute to its development;

- openness, tolerance, flexibility, constructiveness, and mobility;

- empathy, the ability to model the atmosphere of creative uplift, inspiration;

- authenticity of professional pedagogical behavior;

- balance, tolerance to entropy, high level of subjective control;

- trust in yourself, others and the World;

- productive cognitive style, critical thinking, high level of social and emotional intelligence,

- ability to reflexively relate their real personal characteristics to the challenges and risks of the present.

The study of professionally significant qualities of teachers allows us to distinguish different categories of teachers: 


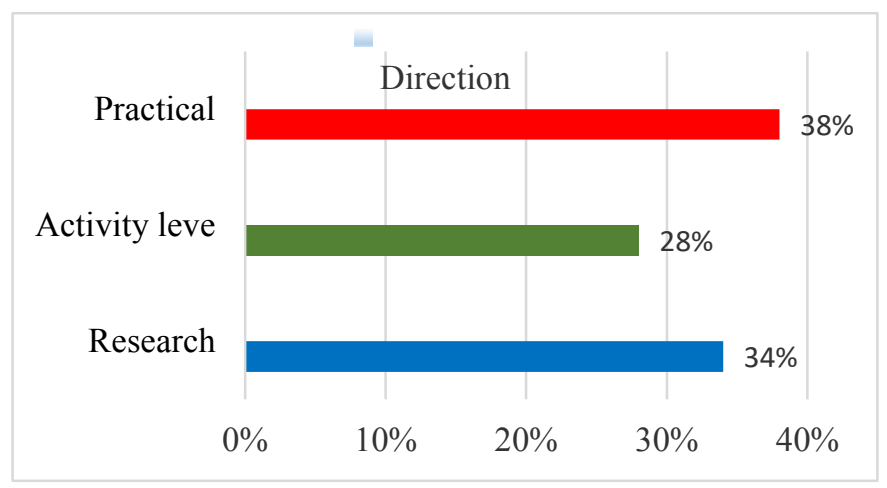

Fig. 1. Professional orientation of teachers.

The teacher of the future in the views of students sociable, committed to social relation recognition, motivated by the approval, by a competent, has real achievements in science and practice, forming a team is easy, tolerant, diploma-TIC communication, able to defend his position, ready to work, considering-et the interests of students, conscientious with a strong sense of duty and responsibility, active, energetic, able to gain credibility quickly resolve practical issues, creative and critical, sustained, really assesses the situation, Toleranten to uncertainty, mobile. This complex also includes the presence of a high level of General, cognitive abilities, insight, reasonableness, creativity, Analytics, and willingness to experiment

The modern innovative educational environment of the University requires a high level of professional development of specific qualities. In the study of the expectations of firstyear students regarding teachers, a number of such qualities included: psychological readiness for contacts; intelligence; ability to maintain interest and attention, communicative self-control, stress resistance, constructive communication style; ability to control professional behavior, maintain self-control in problematic situations of interaction; attractiveness, emotional contagiousness; empathy, understanding the positions of others, the ability to translate knowledge, understanding, independence, attractiveness.

Based on the results of the survey of students, it can be concluded that there are certain clusters of professional and personal qualities of the teacher's image, which are evaluated as positive or negative. The idea of a teacher plays the role of a regulating factor that encourages or hinders the development of constructive and productive interaction and cooperation.

Table 1. Professionally significant qualities of a teacher

\begin{tabular}{|c|l|}
\hline Clusters & \multicolumn{1}{c|}{ Qualities } \\
\hline \multirow{2}{*}{ Positive } & $\begin{array}{l}\text { "creativity", "competence", "sense of humor", "passion", "having a hobby", } \\
\text { "realism", "curiosity", "ability to recognize mistakes", "self-respect", "trust in } \\
\text { others", "charisma", "ability to set the tone", "optimism". }\end{array}$ \\
\hline Negative & $\begin{array}{l}\text { "self-confidence", "suspiciousness", "intemperance", "indifference", "depend- } \\
\text { ence on society", "bias", "arrogance", "rigidity", "coldness", "anxiety", "inde- } \\
\text { cision", "authoritarianism", "irascibility", "lack of organization", "nervous- } \\
\text { ness", "untruthfulness", "absent-mindedness", "self-doubt", "distrust of oth- } \\
\text { ers", "lack of a clear position». }\end{array}$ \\
\hline
\end{tabular}

\section{Discussion of results}

Analyzing the results of the research, it should be emphasized that the main tool of a teacher is his / her personality, so the completeness and integrity of the teacher's personality is 
important for the effectiveness of professional pedagogical activity in cooperation and requires constant improvement.

Subjective limitations and risks are the objective basis on which a complex of individual difficulties and barriers to successful and effective professional activity is formed.

In the space of innovations, the variety of pedagogical technologies and methodological approaches actualizes such qualities of a teacher as the ability to set adequate goals, flexibility, independence, critical and reflexive thinking, constant professional and personal growth, and resistance to the situation of uncertainty.

Of particular importance is the subjectivity of the teacher, which is manifested in: - active, clear orientation in the innovation space;

- reflection on the structure of one's own activities, resources and risks of the innovation space, and features of one's professional identity;

- the adequacy of the assessment of the level of their competence, the ability to reflexively assimilate the experience of others.

The criteria for assessing professional identity are a number of subjective indicators: satisfaction with the activity, profession, career, their status, self-esteem as a professional, self-realization and self-actualization indices of the individual.

Currently, the issue of free, independent development of the teacher is being updated, which gives certain advantages:

- the teacher independently determines the vector of their professional and personal growth, acting as an active subject of professional self-determination and self-development;

- in the process of self-development, the teacher develops a sense of social and professional responsibility for the quality of their activities;

- self-developing teacher builds, as a rule, an effective individual style.

Subject-developing potential teaching profession, the priorities of professionalization of the teacher associated with changes in the internal it world of the person that initiated it in the course of professiogenesis and also with the growth of subjectivity in the formation of its own research and pedagogical practices.

For the future teacher, it is important to be able to combine and analyze various logical schemes, positions and opinions, focusing on the qualitative solution of innovative professional tasks. Since professionalism is evaluated taking into account the effectiveness of the teacher's activity.

As effective methods of self-development of the teacher can be identified such as: the implementation of a professional plan, the presence of a subjective scenario of professional life; overcoming barriers of consciousness, getting rid of" motives of false selfactualization", myths, phantoms of consciousness.

Modern psychology emphasizes the idea that responsibility allows you to correlate and measure your own abilities and capabilities with the requirements of the outside world, society, and other people, and thus increase the chances of success.

In teaching, this is of particular importance, since the teacher can solve problems of increased complexity, predict the development of events and build adequate models of interaction with students due to high intelligence. What is important here is how much the teacher is aware of the need for continuous intellectual enrichment in the process of ontogenesis.

\section{Conclusions}

The study of the personality image of the teacher of the future in the students ' ideas about him is of great importance for improving the quality of training of specialists at the University. This is primarily due to the fact that the student focuses on the reference teacher, tries to imitate him, thereby building the trajectory of his professional development, forming an 
image of achievements. Psychologists consider imitation as an important mechanism of socialization, due to which there is a conscious or unconscious development of external methods of behavior, communication, activity, and ways to achieve success.

It should be noted that at high levels of professionalism, personal characteristics: courage, creativity, independence, perseverance have a greater impact on achieving high results than intellectual characteristics. In modern conditions, the role of social intelligence as one of the fundamental factors of professional, social and personal success of the subject of life activity increases, since all activities here are based on pedagogical and social interaction and the ability to show social competence in difficult situations.

In ensuring the success of a teacher's professional activity in a modern University, the ability to show independence in correcting goals, choosing a way to solve professional problems and determining the trajectory of their own development, the ability to show independence in developing an optimal individual style and individual concept of teaching activities, the ability to become an "achieving person" focused on success and perspective, focusing her attention on the possibility of improving the level of task performance.

The image of the teacher of the future is initially formed under the influence of social projects, reference teachers, who are personified with an attractive image of the teacher, a model broadcast by the media. This image is dynamic, its content can be set by the actual situation of interaction with specific higher school teachers operating today.

The student at certain stages of development shows the ability not only to recognize the determinants and mechanisms of success, consciously form an image that contributes to success, to comprehend, model, plan and implement these ideas, setting development goals, focusing on a teacher who can purposefully influence themselves, their behavior, and therefore their future, achieving success.

For successful pedagogical activity and social activity of a teacher, it is important to form an adequate individual attributive style, awareness of professional prospects. The results of the analysis allow us to conclude that the professionalism of the teacher's personality is associated with the ability to self-movement, self-development, self-realization, and the formation of the subject of individual professional activity. The student, in cooperation with the teacher, solves a number of tasks: predicting the possible future; understanding and reflecting on the current situation; making a decision about the individual development trajectory; correlation of goals and tasks with resources and competence level; identification of own resources and risks; regulation and control of activity taking into account predicted changes.

\section{References}

1. O. A. Demina, I. A. Tepleneva Higher education in Russia, 7, 156-167 (2020)

2. I. B. Kotova, Proceedings of the Southern Federal University. Pedagogical science, 5, $65-72$ (2013)

3. A. G. Asmolov, Optics of Enlightenment: Sociocultural - Moscow: Enlightenment, 447 (2015)

4. E. V. Ezhak, Professional development of a teacher: mechanisms, resources and risks Rostov n/D: publishing center of DGTU, 175 (2015)

5. D. N. Misirov, Proceedings of the Southern Federal University. Pedagogical Sciences: scientific and pedagogical journal. - Rostov-on-Don: publishing house of the southern Federal University (2011)

6. T. Scherbakova, D. Misirov, M. Akopyan, L. Ogannisyan, E3S Web Conf., 175 (2020) 15013 DOI: https://doi.org/10.1051/e3sconf/202017515013 
7. T. N. Shcherbakova, T.V. Loboda, D. N. Misirov, SHS Web of Conferences (2019) 70:0101 DOI 10.1051/shsconf / 20197001015

8. G. G. Sirenko, S. N. Malinetskii, The World Is Russia, 2, 92-107 (2020)

9. E. V. Roschevskaya, Izvestia of the southern Federal University. Pedagogical science. Rostov n /D: Publishing house of SFU, 9, 109-116 (2013)

10. I. V. Abakumova, General theory of meaning, psychological concepts of meaning formation, meaning didactics: (Ed. "Credo", Moscow), 430 (2013)

11. D. A. Leontieva, Personal potential: structure and diagnostics, 680 (Moscow, Smysl, 2011)

12. L.A. Ogannisyan, Y. P. Borzilov, S. V. Semergey, D. N. Misirov, M. A. Akopyan, The 6th International Conference on Management and Technology in Knowledge, Service, Tourism \& Hospitality, Kuta (Bali, Indonesia, 2018)

13. V. A. Terkina, Analytics of cultural science, 2(32), 12-17 (2015)

14. T. N. Shcherbakova The success of a teacher in a multicultural educational environment: diagnostics, development technologies, 312 (Rostov-on-don: Publishing house of the state University of RPK and PPRO, 2019)

15. T. N. Shcherbakova, R. Kh. Malkarova, A. B. Sozaev, M. A. Anayev, R. Kh. Kulimova, S. M. Khakhetlova, Journal of Advanced Research in Dynamical and Control Systems presents peer-reviewed survey and original research articles. ISSN 1943023X Coverage 2009-2015 (2017-2020) 